\section{The Microscopy Society Of America Project MICRO}

\author{
Caroline Schooley \\ Project MICRO Coordinator \\ schooley@mcn.org
}

The Microscopy Society of America (MSA) is a vigorous professional society of close to 3000 members, founded more than a half century ago. The membership is an unusual mix of scientists, engineers, and technologists in diverse fields of biological, materials, medical, and physical science and technology.

Education is a primary function of a scientific society. Microscopists exchange professional information at meetings and in technical publications, but MSA is also very conscious of the importance of improving the scientific awareness of the general public. MSA has chosen to do so with an educational outreach program at the middle school level, called Project MICRO (Microscopy In Curriculum - Research Outreach). Our goal is to place MSA-member volunteers in the classroom, to help teachers use microscopes to introduce scientific inquiry.

Rather than attempting to create a program independently, we chose to collaborate with the outstanding educators at the Lawrence Hall of Science (LHS) on the development of a GEMS (Great Explorations in Math and Science) manual that uses microscopes to introduce scientific observation and inquiry. It was a wise choice; Microscopic Explorations has sold 11,000 copies since 1998 and is now in its third printing.

\section{What is Project MICRO?}

Project MICRO (Microscopy In Curriculum - Research Outreach) is the Microscopy Society of America's outreach program for middle schools. It provides teachers with both microscopybased teaching materials and member-volunteers to help in the classroom.

Middle school teachers need more help than high school teachers; even if they're "science specialists" most don't have adequate background. And since middle school students are taking general science, rather than elective sciences, it's possible to reach them all. MICRO's goal isn't to teach microscopy; the microscope is used as an exciting "tool of science" to introduce critical observation and inquiry.

Teachers need curriculum materials that present science as classroom-tested units which work reliably and require a minimum of pre-class prep time. MSA's Microscopic Explorations was written for grades 4-8; there is a real need for both curriculum material and teacher development at that level. It was written in collaboration with the science education specialists at the Lawrence Hall of Science (LHS), as part of the LHS GEMS (Great Explorations in Math \& Science) program. The LHS is an organization that has an earned national reputation for both the preparation of teaching materials and the education of teachers in their use; they function on a national level.

\section{MICRO and GEMS}

The Lawrence Hall of Science (LHS) is an international leader in science education. In 2001, its GEMS (Great Explorations in Math and Science) program was named one of nine "exemplary and promising" national programs by the U.S. Department of Education. LHS has set the standard for an activity-based, inquiry-driven

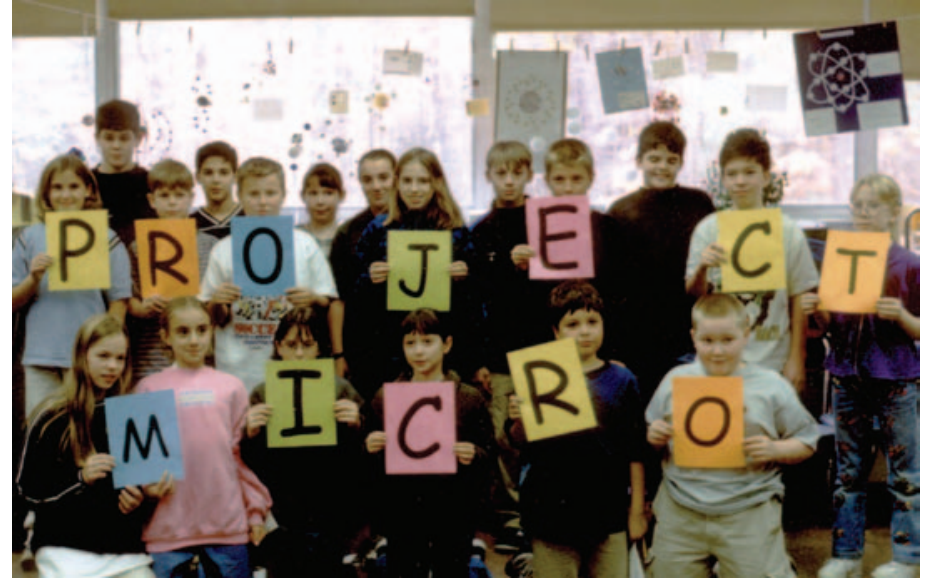

Sixth grade class, Essex Middle School, Essex, Vermont. Photographer/ Volunteer: Janet Schwarz.

approach to teaching science. LHS materials are used in a third of the nation's schools.

GEMS began in 1984, and its influence has expanded rapidly in recent years. The program now includes a series of more than 80 teachers' guides and handbooks; more than 1.5 million copies of GEMS guides have been printed. The GEMS national network is unique in U. S science education; there are more than 2600 Associates who train other teachers in inquiry methods, and over 20,000 Leaders who know how to use GEMS in the classroom. More than 60 regional Sites and Centers provide direct support to teachers and other educators; a Site has two or more GEMS-trained Associates, and Centers have a larger staff and more extensive GEMS initial training. This network can help volunteers to learn how to be effective in a classroom, and find teachers who want help. It is estimated that more than 700,000 teachers and 12 million students have experienced GEMS activities. MSA/MICRO's Microscopic Explorations is accepted for use in almost any school district, as part of the GEMS series. Together with GEMS, MSA/MICRO is presenting microscopy as an engaging and enlightening inquiry activity, reaching many more thousands of students each year.

\section{Local Outreach Programs}

Several of MSA's local societies and one university now have outreach programs; they are all a bit different. If you want advice on how to organize a workshop, contact the Burlington, Vermont program; New England has been very successful at fundraising, Minnesota has an outstanding website, and Cornell has used grad students as volunteers effectively. If you want to join one of the programs, or if you want to learn more about what they're doing, please contact the program chairs. You'll find current information on the MICRO website.

\section{How Can I Help MICRO?}

Be A Volunteer

- Join one of MSA's local programs, or help develop a new one.

- Work with an existing outreach program sponsored by your university or employer.

- Help a GEMS Associate present teacher workshops.

- Use Microscopic Explorations independently. The reputation of GEMS will help you begin a relationship with a hesitant teacher.

Don't be casual about volunteering; realize that you're making a commitment that will take time and effort. Look at the RISE (Resources for Involving Scientists in Education) website of the 


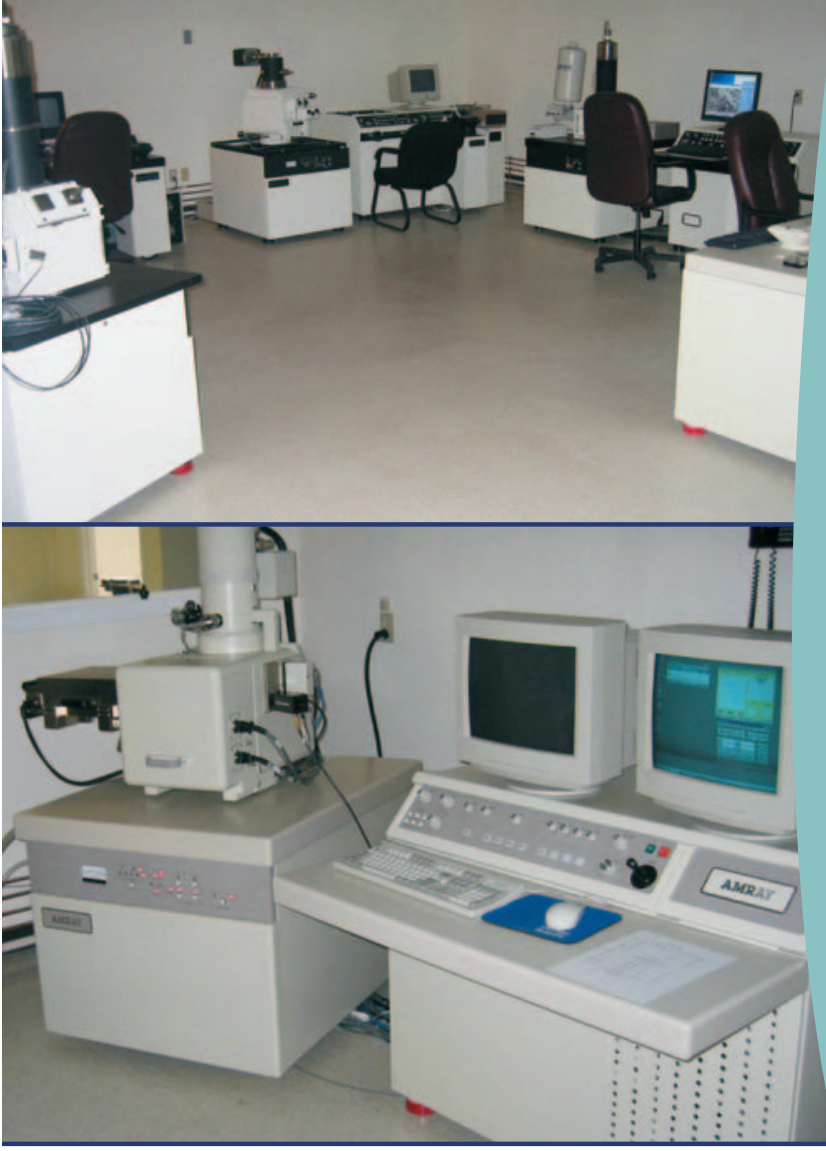

\section{Pre-Owned SEMs -}

\section{The Smart \& Easy Alternative to Buying New}

Why buy a new Scanning Electron Microscope when SEMTech Solutions offers a smarter and easier solution?

We specialize in pre-owned, rebuilt and upgraded products, including:

- Field Emission SEMs

- Digital Imaging

- Computer and EDS Upgrades

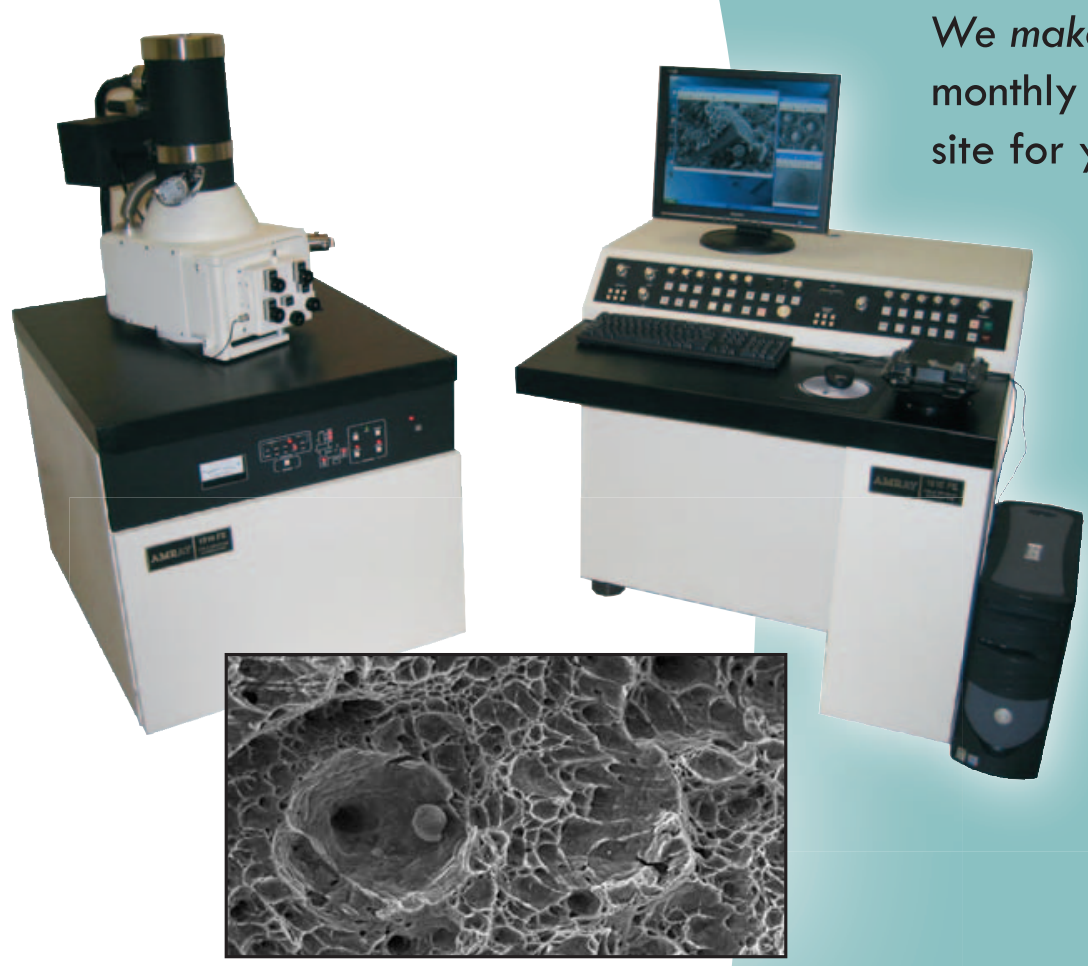

We make it easy by offering hands-on, in-person equipment demonstrations at our Massachusetts facility. Scheduling a demo is simple; just call us at $978 \cdot 663 \cdot 9822$ for an appointment.

Visit us at www.semtechsolutions.com to get more information on all SEMTech Solutions products and services.

Smart. Easy.

- SEMTech Solutions, Inc.

- SEMTech Solutions, Inc.

6 Executive Park Drive

North Billerica, MA 01862

$978 \cdot 663 \cdot 9822$

www.semtechsolutions.com 
National Academy of Sciences, www.nas.edu/rise/chap1.htm Then take an in-depth look at the advice on the MICRO website. I Don't Want To Be A Classroom Volunteer. How Can I Help?

- Assemble a kit of the supplies needed to present Microscopic Explorations. They're low-cost common items, but teachers don't have the time to do it. Give the kit to a school or a GEMS Site.

- Do you like to fix things? Offer to clean or repair microscopes at a school.

- Help a school get microscopes; ask your corporate employer's "community" fund for $\sim \$ 1000$ to buy a classroom set of microscopes for a school.

- Host a class field trip to your microscopy lab. If you choose this option, excellent advice from the National Academy of Sciences will help ensure success.: http://www.nas.edu/rise/ chap4.htm

\section{What Can MICRO Do For Teachers?}

- Provide classroom-tested, standards-based curriculum materials that use microscopes to teach scientific observation and inquiry.

- Provide a microscopist-volunteer to help present Microscopic Explorations.

- Provide advice on selection of school microscopes.

- Provide supplemental materials to expand topics introduced by Microscopic Explorations.

See the MICRO website for all of the above!

\section{Does “Microscopic Explorations” Meet My State's Educa- tion Standards?}

Yes, but all state standards are different. The GEMS program is working on a correlation for all its manuals in all states; see www. lhsgems.org. If your state isn't on the list yet, you can easily match this list (for Microscopic Explorations) with your standards.

Skills

Observing, comparing, measuring, recording data, inferring, analyzing, communicating, manipulating laboratory materials and equipment.

Concepts

Lenses, magnification, images, properties, shape recognition, pattern, similarity, comparison testing, crystals, dissolving, evaporation, aquatic habitats, life cycle, animal structure and behavior, plant structures, research techniques of scientists

Themes

Scale, structure, patterns of change, systems and interactions, diversity and unity.

Mathematics strands

Pattern, measurement, function, geometry

\section{Microscopic Explorations}

is written in "festival" format, with ten explorations that can be presented simultaneously to circulating groups of students, or separately in a classroom. There is a rich assortment of supplemental information on microscopes and how to buy them, curriculum extensions, further reading, and sources of help. The units are more classic than unique; subjects include color printing, fingerprints, pond water, brine shrimp, crystals, etc. Its uniqueness lies in the carefully written "inquiry science" presentation of those topics and the thorough prepublication classroom testing of content that a GEMS guide receives. It will work well in any classroom; teachers aren't expected to have special skills. Grades 4-8.

Susan Brady and Carolyn Willard, 1998; revised printings, 1999, 2003. Microscopic Explorations 165 pp, paperback, 8.5x11", $\$ 21.00$ plus $\$ 4.50$ shipping; copyable Spanish-language student worksheets, $\$ 12.50$ (MSA members may request a 15\% discount on both). ISBN 0-924886-00-5 Lawrence Hall of Science, University of California, Berkeley, CA 94720-5200; (510) 642-7771, www.lhsgems.org, gems@uclink4.berkeley.edu. Also available from many school supply catalogs, the National Science Teachers Association, 800-722-NSTA, and any bookseller.

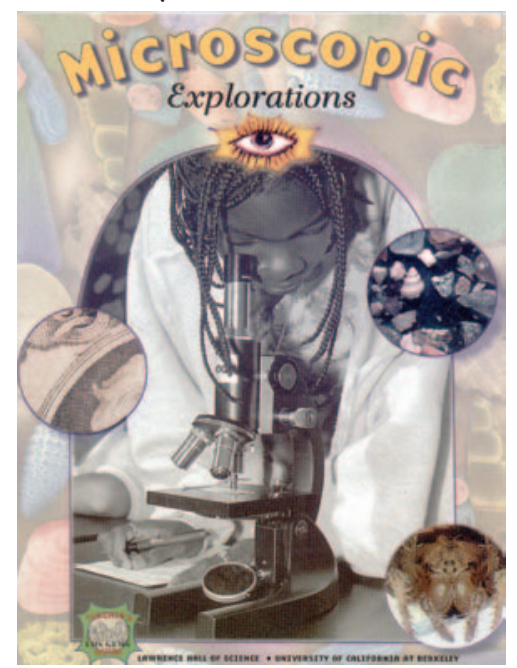

\section{Praise for Microscopic Explorations:}

"Microscopic Explorations is an outstanding example of curricula being prepared for the schools through collaboration between volunteer scientists and professional science educators... it also represents an important device for catalysing the effective participation of scientists throughout our nation with the teachers in their local schools. Intended to interest and involve all students in their middle school years, it is designed to harness the talents of an important scientific society as a resource in educational reform."

Bruce Alberts, President National Academy of Sciences

"Microscopic Explorations is an explicit and extensive resource for science teachers that is easy to use... The book is quality incarnate, there's no question about that."

\section{Appraisal: Science Books for Young People}

"As a community volunteer, I conduct science enrichment programs for elementary school children. I highly recommend Microscopic Explorations as a well-organized tool to introduce students to microenvironments in a fun. learning atmosphere."

\section{Science Books and Films}

\section{Websites}

Program Information:

- Project MICRO (Microscopy In Curriculum-Research Outreach): http://www.msa.microscopy.com/ProjectMicro/PMHomePage.html

- GEMS (Great Explorations in Math and Science):

http://www.lhsgems.org

Advice for volunteers:

- National Academy of Sciences: http://www.nas.edu/rise/chap4.htm

- North Carolina Museum of Life and Science: $\mathrm{http} / / /$ www.noao.edu/education/ncmlssg.html 


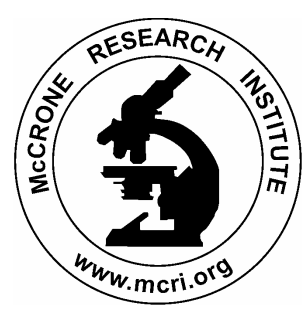

METHODS IN FORENSIC AND TRACE EVIDENCE ANALYSIS

Applied Polarized Light Microscopy (1201) Forensic Microscopy (1204)

January 17-21 March 14-18

April 25-29 June 13-17

July 18-22 Aug. 22-26

October 10-14 Nov. 28-Dec. 2

Advanced Polarized Light Microscopy $\left(1251^{*}\right)$

Advanced Forensic Microscopy (1701)

February 21-25

Chemical Microscopy (1202)

(taught in Ithaca, NY at Cornell University)

August 1-5

Forensic Hair and Fiber Microscopy (1207)

June 27-July 1

Applied Optical Mineralogy (1503)

March 28-April 1

Pollen and Spore Identification (1537)

June 13-17

Wood and Vegetable Fiber Microscopy (1540)

June 27 - July 1

Forensic Microscopy of Glass (1712)

Nov. 28-Dec. 2

Forensic Botanical Microscopy (1720)

September 12-16

Microscopy of Illicit Drugs and Excipients

$\left(1726^{*}\right)$

June 6-10

Forensic Fiber Analysis: Advanced Microscopy and Microchemistry $\left(1507^{*}\right)$

April 25-29

Forensic Paint Microscopy (1715*)

Aug. 29-Sept. 2

Microscopy of Explosives (1722*)

September 19-23

Microchemical Methods (1270A*)

September 26-30

Microscopical /dentification of Asbestos

(1608A)

Jan. 31-Feb. 4 March 21-25

May 2-6 June 20-24

August 8-12 0ct. 3-7

Nov. 7-11

Advanced Asbestos Identification $\left(1608 B^{*}\right)$

February 7-11 Nov. 14-18

\section{CHEMICAL, ENVIRONMENTAL AND BIOLOGICAL HAZARDS}

Microscopy of White Powders (1550*)

January 24-28 June 20-24

Oct. 31-Nov. 4

Microscopy of Spores and Microbiological

Agents (1634)

February 22-24

Microscopy of Explosives (1722*)

September 19-23

Indoor Air Quality: Fungal Spore Identification (1630)

February 14-18 April 4-8

May 16-20 July 25-29

Aug. 29-Sept. 2 October 17-21

December 5-9

Indoor Air Quality: Advanced Funga/ Spore

Identification (1631*)

April 14-16

Advanced Indoor Air Quality: Fungal Culture

Plate Identification (1632*)

March 3-5

Indoor Air Quality: Identification of House Dust and Indoor Particles (1633)

May 5-7 October 6-8

Microscopical Identification of Asbestos

(1608A)

Jan. 31-Feb. 4 March 21-25

May 2-6 June 20-24

August 8-12 Oct. 3-7

Nov. 7-11

Advanced Asbestos Identification $\left(1608 B^{*}\right)$

February 7-11 Nov. 14-18

Asbestos Fiber Counting (NIOSH 582) (1616)

January 24-28 Oct. 31-Nov.4

A custom-designed course held at your facility can be conducted.

Contact Registrar for further details.

\section{METHODS IN MATERIALS SCIENCE}

Applied Polarized Light Microscopy (1201)

Forensic Microscopy (1204)

January 17-21 March 14-18

April 25-29 June 13-17

July 18-22 Aug. 22-26

October 10-14 Nov. 28-Dec. 2

Advanced Polarized Light Microscopy $\left(1251^{*}\right)$

Advanced Forensic Microscopy (1701)

February 21-25

Optical Crystallography and Crystal Morphology $\left(1304^{*}\right)$

August 15-19

Fluorescence Microscopy (1210)

March 22-24 Sept. 8-10

Practical FTIR Microspectroscopy (1421)

April 18-22 Sept. 12-16

Scanning Electron Microscopy and X-Ray

Microanalysis (1402)

May 23-27 Nov. 7-11

Polymer Microscopy (1205)

August 15-19

\section{DIGITAL IMAGING AND SCIENTIFIC PHOTOGRAPHY}

Digital Imaging and Photomicrography (1105)

March 7-11 October 24-28

Advanced Image Analysis and

Photomicrography (1106)

March 16-18

\section{SPECIALTY COURSES}

Particle Isolation, Manipulation and Mounting for Additional Analysis (1501E)

May 9-13 Sept. 26-30

Pharmaceutical Microscopy (1203)

Feb. 28-Mar. 4 Nov. 14-18

Microscopy of Food and Foreign Body

Identification (1560)

September 12-16

Microscopy for Art Conservators (1206)

October 10-14

Conoscopic Methods in Polarized Light

Microscopy $\left(1310^{*}\right)$

January 10-14

More Information about McCrone Research Institute microscopy courses, publications and INTER/MICRO-2005 can be found on our Home Page at: www.mcri.org 